\title{
Research on Equalization of Public Transportation Services Based on Perspective of Groups -- A Case Study of Beijing
}

\author{
${ }^{1 \text { st }}$ Ruijiao Liu ${ }^{1, a},{ }^{2 n d}$ Qiong Tong*2,b, 3rd Jin Tian ${ }^{3, c}$ \\ ${ }^{1}$ the School of Economics and Management, Beijing Jiaotong University, Beijing, China \\ ${ }^{2}$ the School of Economics and Management, Beijing Jiaotong University, Beijing, China \\ ${ }^{3}$ the School of Economics and Management, Beijing Jiaotong University, Beijing, China
}

\begin{abstract}
In this paper, by quantifying the value of public transportation travel benefits of ordinary travel groups, economically disadvantaged groups, and physiologically disadvantaged groups, this paper establishes a public transportation travel benefit evaluation index system, uses a questionnaire survey method to collect index data within Beijing, and establishes a TOPSIS model. Based on the travel benefit values of the three groups, the benefit compensation for disadvantaged traffic groups is considered, benefit compensation factors are introduced, the degree of equalization is evaluated based on the Wilson entropy model, and the level of equalization among public transportation service groups in Beijing is empirically studied to find out an important indicator that restricts the level of equalization.
\end{abstract}

\section{Introduction}

Public transportation is a basic demand in people's daily life. Public transportation service is a social public service provided by the government to all residents. It is generally believed that there should be a universal service obligation, and different groups should be equal. However, there is still a problem of non-equalization in public transportation services in my country. Due to the different levels of development between regions or the imbalance of government investment in transportation, public transportation services between regions cannot be equalized. At the same time, different public transportation services There is also a certain degree of inequality among travel groups. Only by realizing the equalization of public transportation services among the people, and paying special attention to the travel benefits of the disadvantaged groups, can the equalization be truly achieved. In this article, traffic vulnerable groups include physically vulnerable groups and economically disadvantaged groups. Physically vulnerable groups include the elderly and the disabled who need wheelchair assistance to travel. Physically vulnerable groups have travel barriers due to their inconveniences, which are very important for public transportation and service quality. Have special requirements, such as the lack of barrier-free facilities and the loss of public transportation rights; economically disadvantaged groups include low-income groups and student groups who enjoy government subsidies for public transportation. Because of their weak ability to bear the price of transportation services, their travel methods are economically restricted and the level of space accessibility is low. Therefore, a certain amount of public transportation travel subsidies can give economically disadvantaged groups more travel opportunities and longer travel distances.

This paper adopts a quantitative analysis method to evaluate the level of equalization of public transportation services in Beijing city from the group perspective, and explores which factors mainly affect the level of equalization of public transportation services among groups. This paper also puts forward policy recommendations to further improve the level of equalization of public transportation services among groups in Beijing.

\section{Literature review}

Aristotle first expounded the thought of fairness and justice, and put forward the concept of "justice". Rawls put forward the "Justice Theory", using "justice" as the moral standard to evaluate the social system, and proposed the establishment of the principle of equalization of basic public services, that is, the principle of equal benefit, the principle of reasonable preference and the principle of broad subjects.

Scholars pay attention to analyzing the connotation of the equalization of basic public services from the perspective of process, and believe that it is actually a dynamic development process, that is to say, the level of equalization should adapt to the development of the national economy and the financial level, and continue to increase from low to high. Some scholars believes that the equalization of basic public services should be a process at different levels and stages, and the ultimate goal should be the equalization of basic public services between

b* Corresponding author: QingTong, Email: qtong@bjtu.edu.cn

c19113012@bjtu.edu.cn 
regions, between urban and rural areas, and between groups.

There are also certain research results on the public transportation travel of vulnerable groups. In some countries, public transportation protection for people with disabilities and low-income people has been relatively complete. For example, the United States Federal Civil Rights Promotion Act requires people with disabilities to use electronic and information technologies, including IC tags, wireless tags, RFID tags, and other communication devices. The elderly and the disabled can move freely and independently. Scholars mainly focus on accessibility, barrier-free travel facilities, and travel costs for lowincome people. Iwona Sobis1 et al.1 cited an assessment of the local government's achievement of the goals of transportation services for persons with disabilities. In 2013, approximately $3.41 \%$ of citizens used transportation services for persons with disabilities, of which $56 \%$ were elderly people over 80 years old. Wu Lingling et al.2 believe that because the traffic vulnerable groups rely more on non-motorized transportation or public transportation than the average population, promoting the diversity of the transportation system and increasing the accessibility of land use can contribute to the vertical fairness of transportation to a certain extent. The increase of vehicle dependence, on the contrary, measures to increase motor vehicle dependence will reduce vertical fairness.

\section{Calculation method of Public transportation travel benefit}

\subsection{Group division and index system establishment}

According to relevant literature results3, this article takes Beijing public transportation travel groups as the research object, establishes an evaluation index system, and collects public transportation of different groups in Beijing through questionnaires for travel-related information, first divide different travel groups. According to relevant research literature, travel groups are divided into ordinary travel groups, economically disadvantaged groups, and physiologically disadvantaged groups. Physiologically disadvantaged groups refer to groups who are inconvenient in transportation due to their own physical conditions and other reasons. In this article, physiologically disadvantaged groups include the elderly and the disabled who need wheelchair assistance to travel. According to the relevant data of the "Beijing Aging Career Development Report (2018)", as of the end of 2018, the number of elderly people aged 60 and above registered in Beijing was 3.491 million, accounting for $25.4 \%$ of the total registered population in Beijing. According to the data of the "2018 Beijing Disability Prevention Work Report" released by the Beijing Disabled Persons' Federation, as of the end of 2018, there were 526,000 disabled persons with certificates in Beijing.
According to the Beijing Human Resources and Social Security Bureau in 2018, the average salary of full-caliber urban employees in Beijing is 94258 yuan, and the average monthly salary is 7855 yuan. The low-income group in this article is lower than $80 \%$ of the city's average monthly salary, taking into account the survey data Accessibility is defined as the group whose monthly income is less than 6000 yuan/month.

The 20 public transportation travel benefit evaluation indicators selected in this paper are shown in Table 3-1. Among them, the innovative indicators proposed in this paper include the ratio of $\mathrm{C}_{3}$ public transportation expenses to the city's minimum wage level, $\mathrm{C}_{12}$ pedal facilities for wheelchairs to get on and off, and $\mathrm{C}_{13} \mathrm{~A}$ facility with a fixed wheelchair position, and a reminder of the arrival time of the bus when waiting for the $\mathrm{C}_{18}$.

Table I. Evaluation Index and Literature Basis of Public Transportation Travel Benefit

\begin{tabular}{|c|c|c|}
\hline & $\begin{array}{l}\text { Index } \\
\text { classification }\end{array}$ & Index \\
\hline \multirow[t]{2}{*}{ Trip cost } & $\begin{array}{l}\mathrm{B}_{1} \quad \text { Economic } \\
\text { expenditure }\end{array}$ & $\begin{array}{l}\mathrm{C}_{1} \text { Average one-way commute } \\
\text { bus fare } \\
\mathrm{C}_{2} \text { Monthly bus expenses } \\
\mathrm{C}_{3} \text { The ratio of public } \\
\text { transportation expenses to the } \\
\text { city's minimum wage level }\end{array}$ \\
\hline & $\mathrm{B}_{2}$ Time costs & $\begin{array}{l}\mathrm{C}_{4} \text { One-way commute time } \\
\mathrm{C}_{5} \text { Number of one-way transfers } \\
\mathrm{C}_{6} \text { One-way transfer waiting } \\
\text { time } \\
\mathrm{C}_{7} \text { Distance between residential } \\
\text { area and nearest bus stop }\end{array}$ \\
\hline \multirow[t]{3}{*}{$\begin{array}{l}\text { Travel } \\
\text { income }\end{array}$} & $\begin{array}{l}\mathrm{B}_{3} \text { Transportation } \\
\text { quality }\end{array}$ & $\begin{array}{l}\mathrm{C}_{8} \text { Driving safety } \\
\mathrm{C}_{9} \text { On-time departure rate } \\
\mathrm{C}_{10} \text { Frequency of departure } \\
\mathrm{C}_{11} \text { Congestion }\end{array}$ \\
\hline & $\begin{array}{l}\mathrm{B}_{4} \text { Transportation } \\
\text { environment }\end{array}$ & $\begin{array}{l}\mathrm{C}_{12} \text { Pedal facilities for } \\
\text { wheelchairs to get on and off } \\
\mathrm{C}_{13} \text { Facility for fixed wheelchair } \\
\text { position } \\
\mathrm{C}_{14} \text { Barrier-free facilities around } \\
\text { the site } \\
\mathrm{C}_{15} \text { Traffic situation around the } \\
\text { site }\end{array}$ \\
\hline & $\begin{array}{l}\mathrm{B}_{5} \text { Traffic service } \\
\text { quality }\end{array}$ & $\begin{array}{l}\mathrm{C}_{16} \text { Green seat setting } \\
\mathrm{C}_{17} \text { Station waiting seat setting } \\
\mathrm{C}_{18} \text { Bus arrival time reminder } \\
\text { when waiting } \\
\mathrm{C}_{19} \text { Video prompt of arrival in } \\
\text { the car } \\
\mathrm{C}_{20} \text { Ride comfort }\end{array}$ \\
\hline
\end{tabular}

From August 2019 to April 2020, a questionnaire survey was conducted in Beijing to obtain research data. The survey sampling adopted a simple random sampling method, and a total of 335 questionnaires were issued. After excluding invalid samples, 307 valid questionnaires were finally obtained, with an effective recovery rate of $91.6 \%$.

The distribution of the three groups in the sample is shown in Table II. 
Table II. Sample Population Distribution Description

\begin{tabular}{|l|l|l|}
\hline Travel group & frequency & percentage $(\%)$ \\
\hline General group & 104 & 33.9 \\
\hline $\begin{array}{l}\text { Economically } \\
\text { disadvantaged group }\end{array}$ & 142 & 46.3 \\
\hline $\begin{array}{l}\text { Physiologically } \\
\text { disadvantaged group }\end{array}$ & 61 & 19.9 \\
\hline total & 307 & 100 \\
\hline
\end{tabular}

Among the surveyed subjects, 149 were males and 158 were females, with a relatively balanced gender ratio. In the age composition, 18-35 years old accounted for half, and the number of other age groups was roughly equal.

The residential locations of the surveyed subjects are relatively even.

After standardizing the deviation of the data, the sample mean data of the corresponding index can be obtained, and then the entropy weight method is used to weight the public transportation travel benefit evaluation index. The original indicator data is formed and normalized, and the difference coefficients of 20 indicators and the weight of the $\mathrm{j}$-th indicator are calculated, as shown in Table III: From the perspective of the entropy weight of the indicator, the economic expenditure indicator occupies the largest weight in the travel benefit evaluation indicator system, with a value of more than $40 \%$.

Table III. Index Entropy Weight

\begin{tabular}{|c|c|c|c|}
\hline Index classification & Index & Weights & Total weight \\
\hline \multirow{3}{*}{ B1 Economic expenditure } & C1 Average one-way commute bus fare & 0.153839 & \multirow{3}{*}{0.401267} \\
\hline & C2 Monthly bus expenses & 0.194983 & \\
\hline & $\begin{array}{l}\text { C3 The ratio of public transportation expenses to the city's } \\
\text { minimum wage level }\end{array}$ & 0.052445 & \\
\hline \multirow{4}{*}{$\begin{array}{l}\text { B2 } \\
\text { Time costs }\end{array}$} & C4 One-way commute time & 0.082658 & \multirow{4}{*}{0.207448} \\
\hline & C5 Number of one-way transfers & 0.076967 & \\
\hline & C6 One-way transfer waiting time & 0.021238 & \\
\hline & C7 Distance between residential area and nearest bus stop & 0.026584 & \\
\hline \multirow{4}{*}{ B3 Transportation quality } & C8 Driving safety & 0.022822 & \multirow{4}{*}{0.131434} \\
\hline & C9 On-time departure rate & 0.035547 & \\
\hline & C10 Frequency of departure & 0.033521 & \\
\hline & C11Congestion & 0.039544 & \\
\hline \multirow{4}{*}{$\begin{array}{l}\text { B4 Transportation } \\
\text { environment }\end{array}$} & C12 Pedal facilities for wheelchairs to get on and off & 0.058555 & \multirow{4}{*}{0.164264} \\
\hline & C13 Facility for fixed wheelchair position & 0.050798 & \\
\hline & C14 Barrier-free facilities around the site & 0.035560 & \\
\hline & C15Traffic situation around the site & 0.019352 & \\
\hline \multirow{5}{*}{ B5 Traffic service quality } & C16 Green seat setting & 0.022691 & \multirow{5}{*}{0.095587} \\
\hline & C17 Station waiting seat setting & 0.016577 & \\
\hline & C18 Bus arrival time reminder when waiting & 0.019994 & \\
\hline & C19 Video prompt of arrival in the car & 0.015558 & \\
\hline & C20 Ride comfort & 0.020767 & \\
\hline
\end{tabular}

Among the economic expenditure indicators, the public transportation expenses in $\mathrm{C} 2$ accounted for the largest weight, and the average one-way commute bus expenses in $\mathrm{C} 1$ also accounted for a larger weight. The weight of the ratio of public transportation expenses to the city's minimum wage level in $\mathrm{C} 3$ was lower than the other two in the economic expenditure indicators. Indicators.

Among the time cost indicators, C4 one-way commuting time and C5 one-way transfer times have higher weights, $\mathrm{C} 6$ one-way transfer waiting time, and the distance between $\mathrm{C} 7$ residential area and the nearest bus station is lower. C4 One-way commuting time indicator. The longer the commuting time, the lower the travel benefit. If the one-way commuting time can be reduced during public transportation travel, the travel benefit will be significantly improved. On the way of public transportation, the transfer behavior also increases the time cost of the travel itinerary, and the increase in the number of transfers will also lead to a significant reduction in travel benefits. C6 One-way transfer waiting time, the current public transportation (including regular buses and subways) has been more intensive, and there are multiple public transportation lines for residents to choose to travel, but reducing the waiting time for transfers can also improve travel to a certain extent benefit.

Among the transportation quality indicators, the weights of $\mathrm{C} 8$ driving safety, C9 departure punctuality rate, $\mathrm{C} 10$ departure frequency, and $\mathrm{C} 11$ congestion have 
little difference, and the values are basically 0.22-0.33. The weight of C8 driving safety is lower than that of C9 departure on time. Three indicators: speed, C10 departure frequency, and $\mathrm{C} 11$ congestion.

In the transportation environment index, the weights of C12 pedal facilities for wheelchairs to get on and off the car and $\mathrm{C} 13$ fixed wheelchair position facilities are basically the same, about 0.05 , the index weight of the obstacle-free facilities around the $\mathrm{C} 14$ station is 0.35 , and the traffic condition around the $\mathrm{C} 15$ station is weighted. The lowest is about 0.01 .

Among the traffic service quality indicators, the weights of the five indicators are relatively low, and the value ranges from 0.15 to 0.22 .

\subsection{TOPSIS model measures travel benefits}

TOPSIS method is also called "approximate ideal solution sorting method", which is an effective method for solving multi-objective decision-making problems. After forming the weighted main diagonal matrix and constructing the evaluation matrix based on entropy weight, suppose the decision problem has $\mathrm{m}$ goals and $\mathrm{n}$ feasible solutions, and then assume that the ideal solution of the normalized weighted goal of the problem is $Z^{*}$, and the positive ideal solution is $\mathrm{Z}^{+}$, The negative ideal solution is $Z^{-}$. Using the Euclidean norm to measure the distance, the distance from any feasible solution $\mathrm{Z}_{\mathrm{i}}$ to $\mathrm{Z}^{+}$can be calculated as:

$$
D_{\mathrm{i}}^{+}=\sqrt{\sum_{\mathrm{j}=1}^{n}\left(Z_{i j}=Z_{j}^{+}\right)^{2}}, i=1,2, \ldots, \mathrm{m}
$$

In the same way, the formula for the distance between any feasible solution $\mathrm{Zi}$ and the negative ideal solution $\mathrm{Z}$ is:

$$
D_{\mathrm{i}}^{-}=\sqrt{\sum_{\mathrm{j}=1}^{n}\left(Z_{i j}=Z_{j}{ }^{-}\right)^{2}}, i=1,2, \ldots, \mathrm{m}
$$

Let $\mathrm{Ci}$ be the closeness of the evaluation object to the ideal solution, and its value range is between $[0,1]$, and the relative closeness calculation formula is:

$$
\mathrm{C}_{\mathrm{i}}=\frac{D_{\mathrm{i}}^{-}}{D_{\mathrm{i}}^{-}+D_{\mathrm{i}}^{+}}, 0 \leq C_{\mathrm{i}} \leq 1, \quad \mathrm{i}=1,2, \ldots, \mathrm{m}
$$

On the basis of calculating the discount progress of each sample and the ideal solution, the average closeness of the general travel group, the economically disadvantaged group, and the physiologically disadvantaged group are respectively calculated, as shown in Table IV. The data in the table shows that the benefits of public transportation travel for each group are different, with the economically disadvantaged group being the highest, the ordinary travel group in the middle, and the physiologically disadvantaged group the lowest.

Table IV. Trip Benefit Value After Normalization

\begin{tabular}{|c|c|}
\hline Travel group & Travel benefits \\
\hline General group & 0.410126 \\
\hline $\begin{array}{c}\text { Economically } \\
\text { disadvantaged group }\end{array}$ & 0.462116 \\
\hline $\begin{array}{c}\text { Physiologically } \\
\text { disadvantaged group }\end{array}$ & 0.387277 \\
\hline
\end{tabular}

\section{Wilson entropy model equalization level evaluation}

In the research of this article, assuming that public transportation travel is also a distribution problem for the benefit distribution of different groups, then the equilibrium of benefit distribution can be measured by the maximum entropy model. Assuming that the distribution of benefits brought by urban transportation public services among different groups conforms to the Wilson entropy distribution, a Wilson entropy model can be established to measure the equality of this benefit distribution.

The model of the level of equalization among public transportation service groups constructed in this paper is:

$$
\begin{gathered}
\mathrm{S}=-\sum_{i=1}^{n} \frac{M_{i}\left(\ln M_{i}-\ln F_{i}\right)}{F_{i}} \\
Z=\frac{S}{S_{\max }}
\end{gathered}
$$

Among them, $\mathrm{S}$ is the entropy value of Beijing public transportation travel benefits distributed among groups, $\mathrm{M}_{\mathrm{i}}$ is the benefits brought by public transportation services to each group; $F_{i}$ is the benefit compensation factor, which represents the compensation for the traffic vulnerable groups, $F_{i} \geq 1$ and $F_{i}$ the larger the compensation, the more compensation. $Z$ represents the equalization level of public transportation services, $0 \leq Z \leq 1$, the larger the $Z$ value, the closer the actual entropy value is to the maximum entropy value, that is, the larger the $\mathrm{Z}$ value, the more equalization; $S_{\max }$ is the maximum value under constraints. The maximum entropy value corresponding to the optimal allocation, that is, the entropy value in the most even case, the constraint conditions are:

$$
\sum \frac{M_{i}}{F}=1
$$

and $0 \leq \mathrm{M}_{\mathrm{i}} \leq 1$.

Suppose the public transportation travel benefits of ordinary travel groups, economically disadvantaged groups, and physiologically disadvantaged groups are $\mathrm{X}_{1}, \mathrm{X}_{2} \ldots \mathrm{X}_{\mathrm{n}}$, and normalize the travel benefits of these three groups. The principle of The normalization method is: transform the positive term sequence $\mathrm{X}_{1}, \mathrm{X}_{2}, \mathrm{X}_{3}$

$$
G_{i}=\frac{X_{i}}{\sum_{i=1}^{n} X_{i}}
$$

After normalizing $\mathrm{X}_{1}, \mathrm{X}_{2}, \mathrm{X}_{3}$ and calculating the $\mathrm{Fi}$ benefit compensation factor, the results are as follows:

Table V. Trip Benefit Value After Normalization

\begin{tabular}{|c|c|c|c|}
\hline Index & $\begin{array}{c}\text { General } \\
\text { group }\end{array}$ & $\begin{array}{c}\text { Physiologically } \\
\text { disadvantaged } \\
\text { group }\end{array}$ & $\begin{array}{c}\text { Compensation } \\
\text { factor }\end{array}$ \\
\hline $\begin{array}{c}\mathbf{C}_{12} \text { Green seat } \\
\text { setting }\end{array}$ & 0.7778 & 0.8111 & 1.0429 \\
\hline $\begin{array}{c}\mathbf{C}_{17} \text { Pedal } \\
\text { facilities for } \\
\text { wheelchairs to } \\
\text { get on and off }\end{array}$ & 0.5111 & 0.4667 & 0.9130 \\
\hline
\end{tabular}




\begin{tabular}{|c|c|c|c|}
\hline $\begin{array}{c}\mathbf{C}_{\mathbf{1 8}} \text { Facility } \\
\text { for fixed } \\
\text { wheelchair } \\
\text { position }\end{array}$ & 0.5556 & 0.5000 & 0.9000 \\
\hline $\begin{array}{c}\mathbf{C}_{19} \text { Barrier- } \\
\text { free facilities } \\
\text { around the } \\
\text { site }\end{array}$ & 0.6000 & 0.3583 & 0.5972 \\
\hline Average & 2.4444 & 2.1361 & 0.8739 \\
\hline
\end{tabular}

Due to constraints:

$$
\sum_{\mathrm{i}=1}^{\mathrm{n}} \frac{\mathrm{M}_{\mathrm{i}}}{\mathrm{F}_{\mathrm{i}}}=1
$$

It is necessary to perform a proportional scaling transformation on $\mathrm{F}_{\mathrm{i}}$. The result of the transformation will not change the meaning of the corresponding value for group compensation. The benefit compensation factor after the proportional transformation is shown in Table VI:

Table VI. Benefit Compensation Factor After Equal Proportion Transformation

\begin{tabular}{|l|c|c|c|}
\hline Index & $\begin{array}{l}\text { General } \\
\text { group } \\
\mathbf{F}_{1}\end{array}$ & $\begin{array}{l}\text { Economically } \\
\text { disadvantaged } \\
\text { groups } \mathbf{F}_{2}\end{array}$ & $\begin{array}{l}\text { Physiologically } \\
\text { disadvantaged } \\
\text { group } \mathbf{F}_{3}\end{array}$ \\
\hline $\mathbf{F}_{\mathbf{i}}$ & 1 & 1.7042 & 1.2893 \\
\hline $\begin{array}{l}\mathbf{F}_{\mathbf{i}} \\
\text { after } \\
\text { proportional } \\
\text { transformation }\end{array}$ & 0.7692 & 1.3109 & 0.9918 \\
\hline
\end{tabular}

Substituting the corresponding $\mathrm{M}_{\mathrm{i}}$ and $\mathrm{F}_{\mathrm{i}}$ into the model, the $\mathrm{S}$ value is 0.8109 . According to the maximum entropy theory, when the extreme value of $\mathrm{S}$ achieves the maximum entropy value $S_{\max }$, the benefits of each group are evenly distributed, that is, the benefits of the three groups are equal. At this time, both $M_{i}$ are $1 / 3$ and $F_{i}$ are both 1 ,

$$
\begin{aligned}
S_{\text {max }}= & -\sum_{i=1}^{n} \frac{M_{i}\left(\ln M_{i}-\ln F_{i}\right)}{F_{i}} \\
& =-3 \frac{1 / 3(\ln 1 / 3-\ln 1)}{1} \approx 1.0986
\end{aligned}
$$

So we have:

$$
Z=\frac{S}{S_{\max }}=\frac{0.8109}{1.0986} \approx 0.7381
$$

According to the numerical value of the index, the degree of equalization is divided into 6 levels, as shown in Table VII:

Table VII. Level of Fairness

\begin{tabular}{|l|l|}
\hline Index value & Degree of equalization \\
\hline $0 \leq \mathrm{Z}<0.4$ & Extreme inequality \\
\hline $0.4 \leq \mathrm{Z}<0.6$ & Kind of inequality \\
\hline $0.6 \leq \mathrm{Z}<0.7$ & Almost equal \\
\hline $0.7 \leq \mathrm{Z}<0.8$ & More equal \\
\hline $0.8 \leq \mathrm{Z}<0.9$ & Obvious equalization \\
\hline $0.9 \leq \mathrm{Z} \leq 1$ & Extreme equalization \\
\hline
\end{tabular}

According to the model, $0 \leq \mathrm{Z} \leq 1$. The larger the $\mathrm{Z}$ value, the closer the actual entropy value is to the maximum entropy value. In the research of this article, the $Z$ value calculated according to the actual situation in Beijing is 0.7381 , indicating that the group equalization is in It is more equalized, but there is still room for improvement.
On the basis of calculating the benefits of group public transportation trips, the index barriers are analyzed by groups, and the index barriers are calculated, which indicates the degree of barriers to travel benefits by the index value, and diagnoses 20 indicators. Suppose the index obstacle degree is $\mathrm{T}$ and introduce the factor contribution degree $\mathrm{E}_{\mathrm{i}}$ (representing the contribution of a single index $\mathrm{X}_{\mathrm{i}}$ to the total evaluation system, which can generally be expressed by the weight of each index $\mathrm{m}_{\mathrm{i}}$ ), the index deviation degree $S_{i}$ (the gap between the single factor index and the development goal, That is, the difference between the evaluation value of a single index factor and 100\%, which can be expressed by the difference between 1 and the standardized value $X_{i}$ of each index). The calculation formula is as follows:

$$
\mathrm{T}_{\mathrm{i}}=\mathrm{E}_{\mathrm{i}} \mathrm{S}_{\mathrm{i}} / \sum_{\mathrm{i}=1}^{\mathrm{m}}\left(\mathrm{E}_{\mathrm{i}} \mathrm{S}_{\mathrm{i}}\right)
$$

Through the analysis of the obstacle degree of the indicators, we can further find out the important influencing factors that restrict the benefit level of public

\begin{tabular}{|c|c|c|c|c|}
\hline index & $\begin{array}{l}\text { General } \\
\text { group }\end{array}$ & $\begin{array}{c}\text { Economically } \\
\text { disadvantage } \\
\text { d groups }\end{array}$ & $\begin{array}{c}\text { Physiologically } \\
\text { disadvantaged } \\
\text { group }\end{array}$ & total \\
\hline $\begin{array}{c}\mathrm{C}_{1} \text { Average one- } \\
\text { way commute bus } \\
\text { fare }\end{array}$ & 0.5081 & 0.4669 & 0.4674 & 0.4808 \\
\hline $\begin{array}{c}\mathrm{C}_{2} \text { Monthly } \\
\text { public } \\
\text { transportation } \\
\text { expenses }\end{array}$ & 0.4223 & 0.4128 & 0.4440 & 0.4264 \\
\hline $\begin{array}{c}\mathrm{C}_{3} \text { The ratio of } \\
\text { public } \\
\text { transportation } \\
\text { expenses to the } \\
\text { city's minimum } \\
\text { wage level }\end{array}$ & 0.2781 & 0.1949 & 0.2101 & 0.2277 \\
\hline $\begin{array}{c}\mathrm{C}_{4} \text { One-way } \\
\text { commute time }\end{array}$ & 0.3275 & 0.3657 & 0.3225 & 0.3386 \\
\hline $\begin{array}{c}C_{5} \text { Number of } \\
\text { one-way transfers }\end{array}$ & 0.1388 & 0.1877 & 0.1563 & 0.1609 \\
\hline $\begin{array}{c}\mathrm{C}_{6} \text { One-way } \\
\text { transfer waiting } \\
\text { time }\end{array}$ & 0.0476 & 0.0773 & 0.0509 & 0.0586 \\
\hline $\begin{array}{c}\mathrm{C}_{7} \text { Distance } \\
\text { between } \\
\text { residential area } \\
\text { and nearest bus } \\
\text { stop } \\
\end{array}$ & 0.0549 & 0.0893 & 0.0578 & 0.0673 \\
\hline$C_{8}$ Driving safety & 0.0619 & 0.0590 & 0.0874 & 0.0694 \\
\hline $\begin{array}{c}\mathrm{C}_{9} \text { On-time } \\
\text { departure rate }\end{array}$ & 0.0814 & 0.0805 & 0.0780 & 0.0800 \\
\hline $\begin{array}{c}\mathrm{C}_{10} \text { Frequency of } \\
\text { departure }\end{array}$ & 0.0549 & 0.0893 & 0.0578 & 0.0673 \\
\hline $\mathrm{C}_{11}$ Congestion & 0.1542 & 0.1373 & 0.1865 & 0.1593 \\
\hline $\begin{array}{c}C_{12} \text { Pedal facilities } \\
\text { for wheelchairs to } \\
\text { get on and off }\end{array}$ & 0.1201 & 0.1563 & 0.1761 & 0.1508 \\
\hline
\end{tabular}
transportation. Table VIII shows the calculation results of the average obstacle degree value of the 20 index subgroups.

Table VIII. Index Obstacle Value 


\begin{tabular}{|c|c|c|c|c|}
\hline $\begin{array}{c}\mathbf{C}_{13} \text { Facility for } \\
\text { fixed wheelchair } \\
\text { position }\end{array}$ & 0.1513 & 0.1618 & 0.1888 & 0.1673 \\
\hline $\begin{array}{c}\mathbf{C}_{14} \text { Barrier-free } \\
\text { facilities around } \\
\text { the site }\end{array}$ & 0.1360 & 0.1374 & 0.1607 & 0.1447 \\
\hline $\begin{array}{c}\mathbf{C}_{15} \text { Traffic } \\
\text { situation around } \\
\text { the site }\end{array}$ & 0.0576 & 0.0377 & 0.0357 & 0.0437 \\
\hline $\begin{array}{c}\mathbf{C}_{16} \text { Green seat } \\
\text { setting }\end{array}$ & 0.0515 & 0.0733 & 0.0889 & 0.0712 \\
\hline $\begin{array}{c}\mathbf{C}_{17} \text { Station } \\
\text { waiting seat } \\
\text { setting }\end{array}$ & 0.0208 & 0.0310 & 0.0481 & 0.0333 \\
\hline $\begin{array}{c}\mathbf{C}_{18} \text { Bus arrival } \\
\text { time reminder } \\
\text { when waiting }\end{array}$ & 0.0615 & 0.0242 & 0.0549 & 0.0469 \\
\hline $\begin{array}{c}\mathbf{C}_{19} \text { Video prompt } \\
\text { of arrival in the } \\
\text { car }\end{array}$ & 0.0345 & 0.0256 & 0.0401 & 0.0334 \\
\hline $\mathbf{C}_{20}$ Ride comfort & 0.0406 & 0.0666 & 0.0473 & 0.0515 \\
\hline
\end{tabular}

Based on the analysis of indicator barriers and the travel benefits of the three groups calculated in the previous article, it is found that the economically disadvantaged groups have the highest travel benefits, the ordinary travel groups are in the middle, and the physiologically disadvantaged groups are the lowest.The main reason is that the economically disadvantaged groups have the most travel subsidies. At the same time, economic expenditure indicators have the highest overall barriers, so compared to the other two groups, the economically disadvantaged groups can obtain higher travel benefits; for the physically disadvantaged groups, because the current barrier-free facilities services are not perfect, these barriers to barriers Both are higher than the other two groups, so the benefits obtained in public transportation travel will be lower than the other two groups.

\section{Research conclusions and policy recommendations}

\subsection{Research conclusion}

In this paper, by quantifying the value of public transportation travel benefits of ordinary travel groups, economically disadvantaged groups, and physiologically disadvantaged groups, based on the Wilson entropy model to evaluate the degree of equalization, the level of equalization among public transportation service groups in Beijing is evaluated, and the following conclusions are drawn: (1) Residents' satisfaction with services such as reminding the arrival time of buses is low. This reflects that residents have higher requirements for public transportation services. Knowing the arrival time of the bus clearly when waiting for the bus can facilitate residents to arrange travel routes to a certain extent, save travel time and improve travel efficiency. The possible reason for the lower satisfaction with the congestion situation is that from the overall situation of Beijing's ground transportation, the frequency and congestion time of travel are longer, and ground buses are also included, which leads to an increase in travel time. The improvement of station waiting seat service is an important aspect for improving the travel comfort of public transportation, especially for physically disadvantaged groups; (2) There are certain differences in travel benefits between groups. Economically disadvantaged groups have the highest travel benefits, ordinary groups in the middle, and physiologically disadvantaged groups have the lowest travel benefits; (3) Beijing's public transportation services are relatively equal in terms of groups, but there is still room for improvement. (4) The key factors that restrict the level of equalization of different groups are different. For the general group, the subsidy amount of public transportation travel expenditure is lower than that of the economically disadvantaged group and the physiologically disadvantaged group. Therefore, the obstacle degree of the general group is relatively high, and the economic expenditure index is weighted in the public transportation travel benefit evaluation index system. The value is larger, resulting in lower travel benefits for the general group than the economically disadvantaged group. As for the physically disadvantaged groups, the current barrier-free facilities and other services are not perfect, so the benefits obtained in public transportation will be significantly reduced. Therefore, the travel benefits of the physiologically disadvantaged groups are lower than the ordinary groups and economically disadvantaged groups.

\subsection{Policy recommendations}

As a provider of public transportation services, government departments should realize the equalization of public transportation services for all residents. Therefore, they should also pay attention to the interests of traffic vulnerable groups and ensure the supply of public transportation services to traffic vulnerable groups. In order to further improve the level of equalization of public transportation services among groups in Beijing, this article proposes the following policy recommendations:

\subsubsection{Strengthen ba rrier-free facilities services}

China is accelerating its entry into an aging society. The number of elderly people is gradually increasing, and the number of elderly people who need wheelchair-assisted travel has also increased. At the same time, there are also disabled groups who need chair-assisted travel. However, there are certain barrier-free public transportation services. The hysteresis. For physically disadvantaged groups, additional transportation services are needed due to their own particularities, and this type of service is not necessary for ordinary travel groups. Although the provision of barrier-free services is not an "equal" service for everyone, it is promoted in terms of results. Equality among the crowds is ensured, and everyone can enjoy equal public transportation services. Specifically, it includes hardware facilities such as wheelchair fixing 
devices, pedal devices for wheelchairs to get on and off, and site barrier-free environment construction. At the same time, the guidance information services should also be upgraded and perfected, such as barrier-free signs, barrier-free route information inquiry.

\subsubsection{Some public transportation services need to be improved}

Through the investigation of public transportation travel of Beijing residents, the satisfaction of public transportation services such as bus arrival time reminder and congestion situation when waiting for the bus is low, but the current quality of these services needs to be further improved.

The current arrival inquiry service provided by Beijing does not make residents highly satisfied. This service can further improve the punctuality and convenience of arrival time. Regarding the alleviation of ground public transport congestion, Beijing also needs to take measures to ensure public transport priority, set up more public transport roads, optimize public transport road rules and regulations, and improve the operating efficiency of ground public buses. The improvement of the abovementioned public transportation service quality can improve the travel efficiency of the physically disadvantaged groups and ordinary groups to a certain extent, narrow the travel efficiency gap with the economically disadvantaged groups, and promote the level of equalization of public transportation services among groups in Beijing.

\section{Fund project}

Beijing Social Science Fund Project(18JDYJB003)

\section{Reference}

1. Iwona Sobis1,Offolome Guepie Victorien Okouma. Performance Management: How the Swedish Administration of Transportation for the Disabled Succeeded. A Case Study of Transportation Service for the Disabled, the Municipality of Gothenburg[J]. The NISPAcee Journal of Public Administration and Policy, 2017(07) 141-175.

2. Wu Lingling, Zhu Xuemei, Jiang Haiyan. A review of foreign traffic equity analysis theory and methods[J]. Planner, 2014(11): 108-113. [18] Chen Jintan, Cai Shuqin. Highway traffic based on equalization of public services Service Supply[J]. Technical Economy and Management Research,2010,(1):69-76.

3. Zhou Pei, Zhu Xigang, Ma Guoqiang, etc. The travel problems of urban low-income groups and their solutions-Taking Nanjing as an example [J]. Urban Issues, 2013(3): 68-72. 